\title{
MÉTODOS DE AVALIAÇÃO ERGONÔMICA E SUA APLICABILIDADE NA MEDIÇÃO DE DESEMPENHO NA EDUCAÇÃO BÁSICA
}

\author{
MÉTODOS DE EVALUACIÓN ERGONÓMICA Y SU APLICABILIDAD EN LA \\ MEDICIÓN DE DESEMPEÑO EN LA ESCUELA PRIMARIA
}

\author{
ERGONOMICS METHODS AND ITS APPLICABILITY IN PERFORMANCE \\ MEASUREMENT AT ELEMENTARY SCHOOL
}

Tiago Rocha MATIAS ${ }^{1}$

Flávio Anthero Nunes Vianna dos SANTOS ${ }^{2}$

\begin{abstract}
RESUMO: O cruzamento entre métodos avaliativos do campo da Ergonomia e Fatores Humanos com a área da Educação pode trazer maior formalidade a conhecimentos que hoje se apresentam como empíricos; os benefícios desta sistematização integram a possibilidade de reconhecer precocemente fatores de defasagem educacional dos alunos, antes mesmo do processo de alfabetização, contribuindo para o início de políticas de reforço escolar antes do eventual fracasso em provas e trabalhos escritos. Nesta perspectiva, foram analisados os Métodos Ergonômicos da Observação Sistemática, HTA e SAGAT, correlacionados com as práticas docentes de sala de aula no $2^{\circ}$ ano do Ensino Fundamental, objetivando fomentar a formalização dos registros de desempenho discente e apoiar a implementação de técnicas de recuperação e reforço escolar.
\end{abstract}

PALAVRAS-CHAVE: Métodos de avaliação. Observação sistemática. Ergonomia. Educação básica.

RESUMEN: El cruzamiento entre métodos evaluativos del campo de la Ergonomía y Factores Humanos con el área de Educación puede traer mayor formalidad a los conocimientos que hoy se presentan como empíricos; los beneficios de esta sistematización integran la posibilidad de reconocer precozmente factores de desfase educativo de los alumnos, antes del proceso de alfabetización, contribuyendo al inicio de políticas de refuerzo escolar antes del eventual fracaso en pruebas y trabajos escritos. En esta perspectiva, fueron analizados los Métodos Ergonómicos de la Observación Sistemática, HTA y SAGAT correlacionados con las prácticas docentes de aula en el $2^{\circ}$ año de la Escuela Primaria, con el objetivo de fomentar la formalización de los registros de desempeño discente y apoyar la implementación de técnicas de recuperación y refuerzo académico.

PALABRAS CLAVE: Métodos de evaluación. Observación sistemática. Ergonomía. Escuela primaria.

\footnotetext{
${ }^{1}$ Universidade do Estado de Santa Catarina (UDESC), Florianópolis - SC - Brasil. Programa de Pós Graduação em Design - PPG Design. ORCID: https://orcid.org/0000-0002-2262-1751. E-mail: t.matias@yahoo.com.br ${ }^{2}$ Universidade do Estado de Santa Catarina (UDESC), Florianópolis - SC - Brasil. Docente e Pesquisador na UDESC. Doutor em Engenharia de Produção (UFSC). ORCID: http://orcid.org/0000-0002-9670-0954. E-mail: flavio.santos@udesc.br
} 
ABSTRACT: The link between evaluative methods from Ergonomics and Human Factors with the field of Education could provide formality to experiential knowledge; the benefits of this systematization concerns the possibility of early recognition of students' educational lag factors, even before the literacy process, contributing to the early start of strategies for educational improvement, before eventual failure in tests and written assignments. From this perspective, we analyzed the Ergonomic Methods of Systematic Observation, HTA and SAGAT correlated with teaching practices at 2nd Grade Elementary School, aiming to promote the formalization of student performance registers and support the achievement of school recovery and improvement plans.

KEYWORDS: Evaluation methods. Systematic observation. Ergonomics. Elementary school.

\section{Introdução}

De importância crescente no desenvolvimento de recentes políticas públicas brasileiras (SILVA; LEMES, 2016), as avaliações externas na Educação Básica (SAEB, ENEM, Prova Brasil, PISA, entre outros) servem como fonte de informações sobre a qualidade da Educação no país. Nos Anos Iniciais do Ensino Fundamental, há o relato de docentes que acompanham e observam diariamente seus educandos como forma de avaliá-los e acompanhá-los em seu desenvolvimento escolar; neste contexto, os Métodos de Avaliação Ergonômica comparados e adaptados aos Métodos de Avaliação da Educação poderiam contribuir na sistematização deste procedimento observacional, que por muitas vezes se apresenta como conhecimento empírico dos professores, auxiliando na avaliação e compilação dos dados observados de forma que estes possam ser analisados de maneira mais efetiva, fidedigna e verificável. Desta forma, realizamos uma revisão bibliográfica com o objetivo de identificar estudos demonstrando esta sistemática de avaliação na Educação Básica, bem como pesquisas na área da Ergonomia e Fatores Humanos que pudessem relacionar e/ou sugerir Métodos de Avaliação Ergonômica para implementação no contexto de sala de aula.

\section{Métodos de avaliação na educação básica}

Como forma de verificar o sucesso das atividades de aprendizagem no contexto escolar, a avaliação torna-se prática inerente ao desenvolvimento dos alunos. Essa sistemática referencia e promove o entendimento, tanto por parte do educando quanto do educador, da eficácia dos processos desenvolvidos em sala de aula que almejam o entendimento e a apreensão dos conteúdos estudados; apresenta e distingue os conceitos que já foram internalizados dos que ainda necessitam de revisão e reforço. Knijnik, Giacomoni e Stein 
(2013) elaboram um estudo observando a persistência de indicadores relacionados às capacidades cognitivas dos alunos de $1^{\mathrm{a}}$ a $6^{\mathrm{a}}$ séries do Ensino Fundamental, envolvendo critérios de leitura, escrita e aritmética, desde o desenvolvimento do TDE (Teste de Desempenho Escolar) em 1994; esse precursor dos Métodos de Avaliação na Educação tornase ainda hoje, quase 25 anos depois de sua criação, um objetivo ainda atual de requisitos avaliativos, implementados e em discussão e aprimoramento por diversos pesquisadores da área na atualidade (KNIJNIK; GIACOMONI; STEIN, 2013).

Por outro lado, o cotidiano escolar muitas vezes revela desafios nem sempre tangíveis aos pesquisadores e especialistas; conforme relatam Gonçalves e Azevedo (2015, p. 446), "Muitas são as dificuldades que os professores apresentam em como avaliar nos seus alunos [...]". A realidade de sala de aula impõe flexibilidade e geração de alternativas de forma dinâmica pelos professores, que lidam diariamente com alunos que possuem características distintas e precisam ser amparados em sua individualidade pelo sistema educacional, objetivando seu desenvolvimento pleno como cidadão brasileiro. Nesta perspectiva, pode-se considerar comuns os relatos de profissionais da educação que necessitam adequar o seu método de forma a contemplar necessidades não previstas; o caso de alunos em alfabetização, matriculados no $1^{\circ}$ ano do Ensino Fundamental, apresenta uma variável distinta das outras séries deste período escolar: normalmente não existe reprovação de alunos nesta fase, e a avaliação deste grupo poderia tornar-se muitas vezes inerte, pois o aluno não ficaria retido na mesma série mesmo se não atendesse os requisitos propostos. Esse processo poderia de certa forma contribuir para uma flexibilização do rigor avaliativo, e atribuir critérios subjetivos para cumprir a validação do aprendizado adquirido; Gonçalves e Azevedo (2015), em seu estudo, relatam que docentes do $2^{\circ}$ ano do Ensino Fundamental empregam entre suas técnicas avaliativas: observação dos alunos, participação destes nas aulas, sondagens, observação do esforço do aluno e redação de relatórios sobre o desempenho dos educandos. Esses critérios poderiam tornar-se ainda mais significativos caso o aluno desta faixa etária ainda não estivesse alfabetizado; nesses casos, a inviabilidade de uma avaliação escrita, como as técnicas avaliativas propostas pelo TDE (Teste de Desempenho Escolar), não seriam possíveis de serem totalmente implementadas, gerando necessidade de flexibilização e adequação dos testes, ou mesmo impossibilidade de utilização da ferramenta. 


\section{Métodos de avaliação ergonômica}

Desenvolvida logo após a Segunda Guerra Mundial e inicialmente aplicada quase que exclusivamente na indústria (IIDA, 2005),

a Ergonomia (ou Fatores Humanos) é uma disciplina científica relacionada ao entendimento das interações entre os seres humanos e outros elementos ou sistemas, e à aplicação de teorias, princípios, dados e métodos a projetos a fim de otimizar o bem-estar humano e o desempenho global do sistema (ABERGO, 2018, s/p).

A análise do ser humano no desempenho de tarefas específicas relacionadas ao trabalho é um de seus principais campos de estudo, que em grande parte é desenvolvido pelos Métodos Ergonômicos Cognitivos e Comportamentais, métodos estes apresentados pelo pesquisador Neville Stanton (2005), que organizou a publicação "Handbook of Human Factors and Ergonomics Methods".

Os Métodos Ergonômicos Cognitivos e Comportamentais analisam o comportamento humano relacionado às questões de cognição, desempenho e entendimento de tarefas a serem cumpridas por um indivíduo, denominado usuário. Desta forma, os métodos desta categoria empreendem fundamentos que orientam estudos sobre capacidades de atenção, foco e realização de atividades simultâneas, atividades que em muito se assemelham às habilidades necessárias aos estudantes, que precisam se concentrar e direcionar o esforço cognitivo ao entendimento de um conteúdo ou explicação do professor em sala de aula.

Sendo assim, a pretensão desta pesquisa visa associar as tarefas estudadas em Ergonomia voltadas ao desenvolvimento de atividades profissionais usualmente desempenhadas em indústrias, com as necessidades cognitivas necessárias ao bom desenvolvimento acadêmico dos escolares na Educação Básica. A partir desta premissa, estudamos através de uma revisão bibliográfica os Métodos Ergonômicos Cognitivos e Comportamentais que poderiam auxiliar na avaliação destes requisitos em comum (atenção, foco e realização de atividades simultâneas), dentre os quais selecionamos os três que são apresentados a seguir:

\section{Observação sistemática}

A atividade observacional em sala de aula pode proporcionar grande quantidade de dados como suporte à avaliação de alunos. Porém, a atividade deve ser estruturada de forma a contemplar os requisitos relevantes para a aprendizagem dos discentes, e cabe uma análise 
reflexiva e embasada na definição destes critérios. Moraes e Mont'Alvão (2010) defendem que a elaboração prévia do "que" observar é fundamental para o melhor aproveitamento da ferramenta, e uma dedicação anterior à exploração observacional de campo se torna necessária. Superada esta etapa, surge a necessidade de construir um roteiro direcionado a apoiar o processo observacional, onde um pré-questionário ou lista de itens (checklist) pode ajudar uma análise mais efetiva dos alunos, enquanto estes desempenham suas atividades cotidianas da rotina escolar.

\section{Análise Hierárquica da Tarefa (HTA)}

O método de Análise Hierárquica da Tarefa (originalmente denominado em inglês como Hierarchical Task Analysis, que gera a sigla HTA, sendo assim denominado daqui em diante neste artigo) pressupõe um conhecimento elaborado a respeito de uma tarefa a ser desempenhada pelo usuário, de forma que através de uma espécie de fluxograma o passo a passo da atividade se apresente mais claramente visualizável; esta ferramenta pode auxiliar até mesmo a elaboração do roteiro observacional, por permitir uma visualização do contexto das tarefas e uma tomada de decisão mais consciente a respeito das inter-relações entre as muitas atividades relacionadas a uma atividade pedagógica, por exemplo.

\section{Avaliação de Conscientização Situacional Global (SAGAT)}

A técnica do SAGAT (Situation Awareness Measurement and the Situation Awareness Global Assessment Technique), traduzido do inglês para o português como Avaliação de Conscientização Situacional Global, avalia a conscientização do usuário enquanto este desempenha uma tarefa, sendo subdividido em 3 níveis: percepção dos elementos, compreensão da situação e previsão do status futuro. Sua dinâmica ocorre através da aplicação de um questionário envolvendo qualquer um destes 3 níveis, interrompendo a tarefa do usuário e avaliando sua consciência sobre os diversos fatores envolvidos no trabalho que está desenvolvendo.

\section{Cruzamento dos métodos de avaliação ergonômicos $\mathrm{X}$ métodos de avaliação do desempenho escolar na educação básica}

Tendo apresentado neste artigo um resumo dos métodos de avaliação ergonômicos e educacionais voltados à Educação Básica, cumpre papel de destaque a pretensa intenção 
destes pesquisadores de iniciar uma correlação entre os dois campos de conhecimento, almejando um virtualmente possível aproveitamento de saberes de ambas as ciências de forma a contemplar um domínio ampliado das técnicas direcionadas ao desenvolvimento pedagógico de alunos da Educação Básica.

Ferramentas como a Observação Sistemática podem auxiliar o desenvolvimento de estratégias pedagógicas: roteirizar o que avaliar observando os alunos em sala de aula, possibilitaria a sistematização dos resultados obtidos e diminuiria o empirismo na atribuição de conceitos que poderiam inclusive vir a ser questionados, após a aprovação ou reprovação do estudante. Esta técnica contribuiria também no aumento do espectro avaliativo do discente, pois entrariam aspectos como foco e atenção do aluno no conteúdo estudado, que diferem da avaliação puramente seletiva de certo ou errado de uma prova escrita, por exemplo.

O SAGAT, método de avaliar a capacidade de combinar processos mentais presentes e futuros, pode auxiliar o professor a compreender como o aluno absorve o conteúdo apresentado e sistematiza suas tarefas em ordem de execução, o passo a passo que determina as etapas para a conclusão de uma tarefa. Essa informação, comparando os alunos entre si em relação ao resto da turma, forneceria então mais subsídios para entendimento das eventuais falhas de execução de atividades escolares, quando o educando fracassa por não cumprir o estabelecido didaticamente mesmo tendo consciência do conteúdo estudado, ou seja, poderia ser então identificada um equívoco na execução da tarefa.

A Análise Hierárquica da Tarefa (HTA), estabelece ordenadamente todos os passos necessários para o cumprimento de uma tarefa, auxiliando dessa forma a compreensão da atividade e facilitando sua apropriação em métodos como a Observação Sistemática e o SAGAT

Como forma de exemplificar o processo, poderíamos supor a aplicação destes Métodos de Avaliação Ergonômicos no contexto prático de uma sala de aula do $1^{\circ}$ ano do Ensino Fundamental: considerando uma hipotética atividade pedagógica direcionada aos alunos de, por exemplo, recortar figuras de animais, colá-las na folha de papel, desenhar um zoológico, e por fim colorir o trabalho, desencadearia o HTA da seguinte forma:

1- Recorte das figuras (subdividido em selecionar imagem em uma revista ou similar, e utilizar tesoura para cortar);

2- Colagem das figuras (subdividido em escolha das figuras e pré-posicionamento destas na folha - prevendo o posterior desenho do zoológico - aplicação da cola nas imagens, e por fim o próprio processo de colagem no papel); 
3- Desenho do zoológico (utilização de lápis para desenhar os elementos que constituem o zoológico, jaulas, setores, elementos divisórios, etc., bem como elementos ambientais como árvores, céu, sol, nuvens...; emprego de noção espacial de forma a preservar a proporcionalidade entre as figuras dos animais e os espaços desenhados);

4- Colorir o trabalho (utilização de lápis e/ou canetas coloridas ou similares para aplicar cores aos elementos desenhados na folha; preenchimento dos espaços em branco com as tonalidades escolhidas).

Desta forma, o HTA gerado com as etapas e sub-etapas descritas neste nosso exemplo hipotético, que poderia ser visualizado como uma espécie de fluxograma de ações (numerado de 1 a 4), apresenta-se como a primeira etapa de nossa análise: dele extraímos as referências a serem analisadas para nossa Observação Sistemática, que poderia, entre outros itens a serem definidos pelo professor regente, avaliar por exemplo quanto tempo o aluno leva para definir quais imagens irá recortar (neste aspecto um método de cronometragem do tempo pode ser amplamente benéfico no embasamento do estudo, principalmente se comparando o desempenho dos alunos entre si); observar e registrar quantas imagens a criança recortou pertinentes à atividade (animais), e se ela selecionou imagens fora do tema (como carros ou bonecas, por exemplo). A própria postura do aluno revela um fator de avaliação do seu entendimento e foco na tarefa, quando este se mostra visualmente atento aos materiais de estudo ou alheio e observando o que se passa na janela ou nos corredores da escola.

Concluindo, após estabelecermos a sequência de atividades a serem avaliadas através do HTA, e registrarmos os comportamentos da criança utilizando as ferramentas da Observação Sistemática, o outro Método de Avaliação Ergonômico sugerido neste artigo para aplicação na Educação Básica é a Análise de Conscientização Situacional Global (SAGAT), através do qual podemos avaliar a compreensão do usuário sobre os aspectos relacionados à execução de uma tarefa. Neste caso, poderíamos aplicar o SAGAT perguntando para a criança, por exemplo, enquanto ela recorta as imagens de animais para seu trabalho, qual seria sua próxima atividade: se ela respondesse "colar as figuras", estaria adequado ao processo proposto (vide HTA), porém se ela considerasse "colorir" ou "desenhar o zoológico", ou mesmo "recortar imagens de doces", fugiria ao contexto da atividade (pois não seria possível desenhar ou colorir o zoológico sem ter na folha as imagens, sem ter no papel as proporções dos elementos). Da mesma forma o recorte de figuras alheias ao contexto de "animais" também demonstraria certa imprecisão no desenvolvimento da atividade proposta, pois o recorte de elementos que não serão usados na tarefa desperdiçaria tempo na execução do trabalho. 
Desta dinâmica depreenderíamos uma falta de clareza do discente na organização das etapas de sua tarefa; e de certa forma esta situação tenderia a se repetir nas próximas atividades e séries escolares do educando, potencializando a sua dificuldade em compreender conteúdos escolares, que com o passar do tempo aumentam qualitativa e quantitativamente, conforme o aluno vai evoluindo na grade escolar e sendo aprovado de uma série à outra.

\section{Considerações finais}

A dificuldade em avaliar alunos no primeiro ano do Ensino Fundamental, relatada por pesquisadores como Gonçalves e Azevedo (2015), pode ser atenuada com o emprego de ferramentas desenvolvidas para uso na Ergonomia e Fatores Humanos. Estes métodos podem servir de suporte aos docentes desta fase escolar para sistematizar as observações a respeito dos seus alunos, e compará-las com o resto da turma, gerando um banco de dados com a perspectiva de pré-avaliar, sem o uso de provas e notas, como será o desempenho discente no decorrer de sua vida acadêmica. Ou seja, antes mesmo da alfabetização, já seria possível formalizar documentalmente o desempenho cognitivo do aluno em sala de aula, diferentemente do que ocorre com tradicionais ferramentas avaliativas pedagógicas (como o TDE, por exemplo), que exigem quase em sua totalidade uma produção escrita por parte da criança. Esta percepção precoce de uma eventual dificuldade do aluno em acompanhar o nível cognitivo da turma possibilitaria desencadear com antecedência ações de reforço escolar e recuperação do rendimento da criança, antes mesmo dela obrigatoriamente adentrar nas avaliações escritas e formais em sua carreira escolar e possivelmente começar a apresentar notas baixas em provas e trabalhos escritos.

Neste processo, com o auxílio de áreas do conhecimento como a Pedagogia e a Psicologia, poderiam ser elaborados planos de ação voltados ao desenvolvimento de qualidades como foco, atenção e concentração nos conteúdos escolares e nas aulas, visando “corrigir" e equiparar as discrepâncias nas turmas de alunos identificadas pelos Métodos Ergonômicos aplicados em sala de aula. A necessidade deste desenvolvimento por parte de psicólogos e/ou pedagogos prescinde do contexto educacional da Educação Básica, onde se observa uma série de conceitos e conhecimentos específicos que influenciam o aprendizado e são pesquisados e analisados através dos séculos por seus estudiosos. A tomada de decisão efetiva, que com maior embasamento poderá atender ao objetivo principal que é o melhor aprendizado dos alunos, só poderá ser alcançada com a contribuição de pesquisadores que 
considerem e tenham conhecimento de todas as variáveis relacionadas ao processo de aprendizagem.

Portanto, cabe aqui novamente ressaltar que a aplicação dos Métodos Ergonômicos da Observação Sistemática, HTA e SAGAT em sala de aula permitem tão somente um comparativo entre o desempenho cognitivo de indivíduos pertencentes a um mesmo grupo, neste caso escolar, e a geração destes dados sistemáticos apoia uma tomada de decisão pertencente a outras áreas do conhecimento, diversas à Ergonomia e Fatores Humanos. Ou seja, a pretensão deste estudo não considera elaborar os critérios que avaliam o desempenho escolar como satisfatório ou não-satisfatório, apenas permite através dos métodos apresentados diferenciar características dos alunos relacionadas a foco, atenção e concentração. Em nossa percepção, estes fatores têm grande influência no desempenho escolar, principalmente no início da vida acadêmica, que, conforme descreveram Gonçalves e Azevedo (2015, p. 463), em sua pesquisa com professoras do Ensino Fundamental, comentou sobre os alunos do $1^{\circ}$ ano: "[...] nesta fase a criança não reprova, visto que é sempre promovida para o ano seguinte". Ou seja, esta "não-reprovação" poderia inibir a geração formal de registros de um eventual desempenho insuficiente; neste caso os registros através dos Métodos Ergonômicos poderiam suprir esta lacuna, sem gerar critérios de reprovação, mas permitindo fomentar processos recuperativos do aluno pela contextualização de algum atraso cognitivo deste em relação ao resto da turma.

Por fim, concluímos considerando que foi atingido o objetivo inicial deste trabalho, que se propôs a correlacionar as áreas da Educação com a Ergonomia e Fatores Humanos no espectro de avaliação de alunos/usuários, tarefa esta que consistiu em uma investigação das metodologias e técnicas avaliativas de ambos os campos do conhecimento citados, sendo estas discorridas e analisadas ao longo do texto deste artigo com a intenção de proporcionar a geração de ferramentas capazes de contribuir com o desenvolvimento educacional de crianças ainda em fase de alfabetização. Nesta investigação, verificamos que os métodos ergonômicos da Observação Sistemática, HTA e SAGAT poderiam então ser adaptados e aplicados de forma a sistematizar e formalizar os indicativos muitas vezes percebidos intuitiva e subjetivamente pelos professores primários a respeito do desempenho de seus alunos, possibilitando assim novas formas e critérios de avaliação alternativos ao trabalho escrito produzido pelo aluno, e desta forma fomentar ações precoces de recuperação e reforço escolar.

Porém, para alcançarmos este cenário e viabilizar o uso da ferramenta como relevante no contexto educacional, cumpre-se como papel fundamental a partir de agora o 
aprimoramento do estudo aqui apresentado por outros profissionais da área educacional, que se apropriem e apliquem em contexto prático (sala de aula) as metodologias propostas e desenvolvam assim novas pesquisas, que forneçam um banco de dados relacionando os fatores identificados como responsáveis por uma eventual defasagem escolar dos alunos. A partir destas observações é que se poderia propor ações corretivas e de incentivo ao reforço escolar, logicamente utilizando-se da ferramenta desenvolvida para monitorar e reavaliar continuamente a eficácia das estratégias empregadas, assim como o próprio desempenho discente.

\section{REFERÊNCIAS}

ASSOCIAÇÃO BRASILEIRA DE ERGONOMIA - ABERGO. O que é Ergonomia? Disponível em: http://www.abergo.org.br/internas.php?pg=o_que_e_ergonomia. Acesso em: 12 nov. 2018.

GONÇALVES, Josiane Peres; AZEVEDO, Tamires Ferreira. Avaliação do desempenho escolar: visão das professoras do segundo ano do ensino fundamental. Revista IberoAmericana de Estudos em Educação, v. 10, n. 2, p. 445-466, 2015. Disponível em: https://periodicos.fclar.unesp.br/iberoamericana/article/view/6026/5398. Acesso em: 27 fev. 2019.

IIDA, Itiro. Ergonomia: projeto e produção. 2. ed. rev. e ampl. São Paulo: Edgard Blucher, 2005.

KNIJNIK, Luiza Feijó; GIACOMONI, Claudia; STEIN, Lilian Milnitsky. Teste de desempenho escolar: um estudo de levantamento. Psico-USF, v. 18, n. 3, p. 407-416, 2013. Disponível em: http://www.scielo.br/scielo.php?pid=S141382712013000300007\&script=sci_abstract\&tlng=pt. Acesso em: 27 fev. 2019.

MORAES, Anamaria de; MONT'ALVÃO, Cláudia. Ergonomia: conceitos e aplicações. 4. ed. Teresópolis: 2AB, 2010.

SILVA, André Luiz da; LEMES, Sebastião de Souza. Uma discussão com vistas ao desenvolvimento de um sistema on-line de avaliação do desempenho escolar: um estudo experimental sobre avaliação de desempenho escolar em rede. Revista on-line de Política e Gestão Educacional, v. 20, n. 2, p. 271-281, maio/ago. 2016. Disponível em: https://periodicos.fclar.unesp.br/rpge/article/view/9463. Acesso em: 27 fev. 2019.

STANTON, Neville; HEDGE, Alan; BROOKHUIS, Karel; SALAS, Eduardo HENDRICK, Hal. Handbook of human factors and ergonomics methods. Boca Raton: CRC Press, 2005. 


\section{Como referenciar este artigo}

MATIAS, Tiago Rocha; SANTOS, Flávio Anthero Nunes Vianna dos. Métodos de avaliação ergonômica e sua aplicabilidade na medição de desempenho na educação básica. Revista Ibero-Americana de Estudos em Educação, Araraquara, v. 15, n. 3, p. 1284-1294, jul./set. 2020. e-ISSN: 1982-5587. DOI: https://doi.org/10.21723/riaee.v15i3.12427

Submetido em: 07/04/2019

Revisões requeridas em: 24/09/2019

Aprovado em: 01/02/2020

Publicado em: 20/02/2020 